\title{
Site effects and soil-structure resonance study in the Kobarid basin (NW Slovenia) using microtremors
}

\author{
A. Gosar \\ University of Ljubljana, Faculty of Natural Sciences and Engineering and Environmental Agency of Slovenia, Seismology \\ and Geology Office, Ljubljana, Slovenia
}

Received: 2 February 2010 - Revised: 30 March 2010 - Accepted: 31 March 2010 - Published: 14 April 2010

\begin{abstract}
The town of Kobarid is located in one of three areas with the highest seismic hazard in Slovenia. It was hit by several 1976-1977 Friuli sequence earthquakes and recently by the 1998 and 2004 Krn Mountains earthquakes which caused damage of intensity up to VII EMS-98 scale. The town is located in a small basin filled with heterogeneous glaciofluvial Quaternary sediments in which site effects due to soft sediments are expected. The existing microzonation which is based on surface geological data only is inadequate, and no borehole or geophysical data are available in the basin that would allow a modelling approach of site effects assessment. The microtremor horizontal-to-vertical spectral ratio (HVSR) method was therefore applied in order to assess the fundamental frequency of the sediments. Investigations were performed on a $100 \times 100 \mathrm{~m}$ dense grid and 106 free-field measurements acquired. Clear HVSR peaks were obtained in the majority of the surveyed area. The eastern part of the basin is characterized by two well separated peaks which indicate distinct shallow and deep impedance contrasts. The iso-frequency map of sediments shows a distribution in a broad range of $1.8-22.2 \mathrm{~Hz}$. The observed frequencies can be related to the total thickness of Quaternary sediments (sand, gravel) in the western part of the basin only. They are deposited over bedrock built of Cretaceous flysch. In the eastern part the obtained fundamental frequencies are influenced by the presence of a shallow conglomerate layer inside sandy gravel or lacustrine chalk. The extent of these layers was not known before. Microtremor measurements were also performed inside 19 characteristic buildings of various heights (from two to four stories), and longitudinal and
\end{abstract}

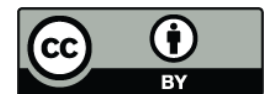

Correspondence to: A. Gosar (andrej.gosar@gov.si) transverse fundamental frequencies determined from amplitude spectra. A potential of soil-structure resonance was assessed by comparing building frequencies with the free-field sediments frequencies derived from the iso-frequency map. For two surveyed buildings a high danger of soil-structure resonance was assessed and for three buildings the danger was of medium level. The building resonant frequency of two- and three-story houses, which prevail in the area, spans the range $4-11 \mathrm{~Hz}$, with an average value of $7.7 \mathrm{~Hz}$. The danger of soil-structure resonance should be therefore sought in this frequency range. Since the majority of Kobarid area is characterized by lower (W part) or higher (E part) frequencies, the danger exist mainly in a relatively narrow transition zone.

\section{Introduction}

In the last decade the microtremor Horizontal-to-Vertical Spectral Ratio method has been widely used for site effect studies (e.g. Bard, 1999). The main advantages of this method are a straightforward estimate of the resonance frequency of sediments without the need to know their thickness and S-velocity structure and simple, low-cost measurements. The use of microtremors was later extended to the identification of the main fundamental frequencies of buildings (e.g. Gallipoli et al., 2004a). Although the theory and interpretation of ambient vibration measurements in buildings are not so elaborated as they are for the free-field measurements, several studies in the last years showed that the microtremor method is useful for the identification of soil-structure resonance.

Published by Copernicus Publications on behalf of the European Geosciences Union. 
In the last 35 years the town of Kobarid in NW Slovenia (Fig. 1) was hit by more then ten strong earthquakes, which caused damage of intensity up to VII EMS-98 scale. Two recent earthquakes with epicentral distances of $7 \mathrm{~km}$ occurred in $1998\left(M_{\mathrm{w}}=5.6\right)$ and $2004\left(M_{\mathrm{w}}=5.2\right)$. Kobarid is thus located in one of the three areas with the highest seismic hazard in Slovenia with $0.225 \mathrm{~g}$ design ground acceleration for a 475-year return period (Lapajne et al., 2001). The town is located in a small basin filled with heterogeneous glaciofluvial Quaternary sediments. For the basin no data are available about the thickness and physical properties of these sediments from drilling or geophysical investigations. The comparison of earthquake damage in Kobarid with that of some nearby villages situated on rock sites indicates the effects of soft sediments on seismic ground motion which enhance the damage. Investigations in the larger Bovec basin $(7 \mathrm{~km} \mathrm{~N}$ from Kobarid) with similar geological setting have shown prominent site effects, complex seismic response and several examples of soil-structure resonance which was presumably responsible for the large variations in damage to buildings related to the 1998 and 2004 earthquakes (Gosar, 2007).

In order to study the effects of Quaternary sediments on seismic ground motion in Kobarid basin, and in view of the fact that no drilling or geophysical data is available that would allow a modelling approach, we decided to perform a study based on the microtremor HVSR method. Previous investigations in the Bovec basin (Gosar, 2007) have shown that due to the heterogeneity of sediments no simple relation between fundamental resonance frequency and the total thickness of Quaternary sediments can be expected in the area. Microtremors were therefore measured on a dense grid $(100 \times 100 \mathrm{~m})$ of free-field points and a map of the fundamental frequency of the sediments was prepared, as well as a map of HVSR peak amplitudes. In addition, microtremor measurements were performed in 19 characteristic buildings to determine their fundamental frequencies. By overlying the resonant frequencies of buildings on the iso-frequency map, a first attempt was made to assess the danger of soil-structure resonance in the basin.

\section{Seismological characteristics}

The Upper Soča valley is located in one of the three areas with the highest seismic hazard in Slovenia. This is mainly due to the proximity of the seismically very active area of Friuli located $30-40 \mathrm{~km}$ to the $\mathrm{W}$ in NE Italy. In this area the $M_{\mathrm{w}}=6.4$ Friuli earthquake occurred in May 1976. The seismic sequence that followed (Table 1) consisted of 6 events of $M_{\mathrm{w}}$ between 5.0 and 6.0 during the same year and one event of $M_{\mathrm{w}} 5.3$ that occurred in September 1997 (Perniola et al., 2004). The intensity of the main shock in Kobarid was VII EMS-98, but the cumulative intensity which includes also damage from aftershocks reached VIII EMS-98.

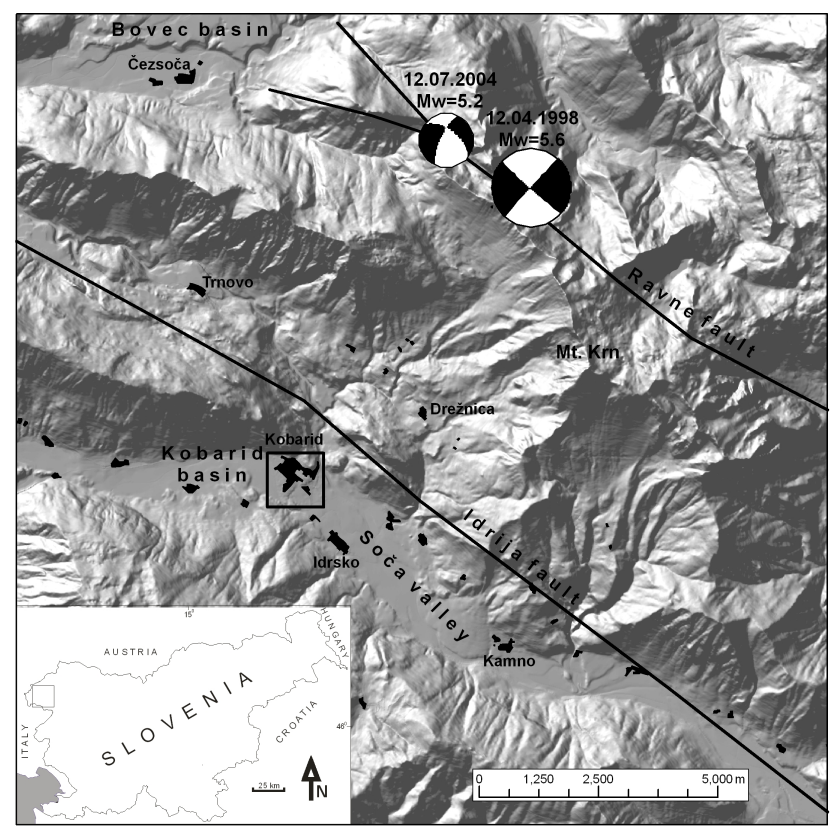

Fig. 1. Shaded relief map of the Upper Soča valley with the Kobarid basin and epicentres of two recent strong earthquakes in Krn mountains. A rectangle indicates study area shown in Figs. 2, 6 and 7.

For the NW Slovenia relatively weak rates of seismicity were assessed before April 1998 when a $M_{\mathrm{w}}=5.6$ earthquake occurred in Krn Mountains only $7 \mathrm{~km} \mathrm{NW}$ from Kobarid (e.g. Bajc et al., 2001). It was followed by a $M_{\mathrm{w}}=5.2$ event in July 2004 in the same epicentral area. Both earthquakes occurred on the NW-SE trending near-vertical dextral strikeslip Ravne fault (Kastelic at al., 2008) at 7.6-11 km depth (Fig. 1). The intensity of the 1998 earthquake in Kobarid was VI-VII EMS-98 (Zupančič et al., 2001) and of the 2004 event VI EMS-98 (Cecić et al., 2006).

NW Slovenia and Friuli region are located at the kinematic transition between E-W striking thrust faults of the Alpine system (Friuli earthquakes) and NW-SE striking strike-slip faults of the Dinarides system (Krn Mountains earthquakes). The strongest earthquake ever recorded in the Alps-Dinarides junction area was the 1511 western Slovenia earthquake $(M=6.8)$; the exact location and mechanism of this event are still debated (Fitzko et al., 2005).

According to the seismic hazard map of Slovenia for a 475-year return period (Lapajne et al., 2001) a design ground acceleration value for a rock site in Kobarid is $0.225 \mathrm{~g}$. The border with the $0.250 \mathrm{~g}$ area in this map is located only $5 \mathrm{~km} \mathrm{~W}$ of Kobarid. Accelerographs were installed in Kobarid after the main Friuli shock in 1976 and after the main Krn Mountains earthquake in 1998. The strongest ground motion in the Friuli seismic sequence was recorded for the 15 September 1976 aftershock $\left(M_{\mathrm{w}}=6.0\right.$, distance $\left.=37 \mathrm{~km}\right)$ as $0.138 \mathrm{~g}$ peak ground acceleration (Ambraseys et al., 2002). 
Table 1. Data for earthquakes with $M_{\mathrm{W}} \geq 5.0$ in the vicinity of Kobarid (after Perniola et al., 2004; Zupančič et al., 2001; Cecić et al., 2006).

\begin{tabular}{lrrrrrrr}
\hline & & & & & & & Intensity \\
Date & Time (UTC) & Lat $\left({ }^{\circ} \mathrm{N}\right)$ & Lon $\left({ }^{\circ} \mathrm{N}\right)$ & Depth $(\mathrm{km})$ & $M_{\mathrm{W}}$ & $\begin{array}{r}\text { Robarid } \\
\text { Region }\end{array}$ & $($ EMS-98) \\
\hline $06 / 05 / 1976$ & $20: 00$ & 46.275 & 13.246 & 6.5 & 6.4 & Friuli & VII \\
$09 / 05 / 1976$ & $00: 53$ & 46.214 & 13.326 & 8.5 & 5.1 & Friuli & \\
$11 / 05 / 1976$ & $22: 44$ & 46.260 & 13.041 & 6.0 & 5.0 & Friuli & \\
$11 / 09 / 1976$ & $16: 31$ & 46.275 & 13.224 & 6.5 & 5.2 & Friuli & \\
$11 / 09 / 1976$ & $16: 35$ & 46.256 & 13.233 & 4.3 & 5.6 & Friuli & \\
$15 / 09 / 1976$ & $03: 15$ & 46.284 & 13.173 & 5.0 & 5.9 & Friuli & \\
$15 / 09 / 1976$ & $09: 21$ & 46.300 & 13.145 & 7.0 & 6.0 & Friuli & \\
$16 / 09 / 1977$ & $23: 48$ & 46.268 & 13.016 & 8.0 & 5.3 & Friuli & \\
$12 / 04 / 1998$ & $10: 55$ & 46.309 & 13.632 & 7.6 & 5.6 & Krn Mts. & VI-VII \\
$12 / 07 / 2004$ & $13: 04$ & 46.310 & 13.620 & 11.0 & 5.2 & Krn Mts. & VI \\
\hline
\end{tabular}

For the 12 July 2004 Krn Mountain earthquake $\left(M_{\mathrm{w}}=5.2\right.$, distance $=7 \mathrm{~km})$ a peak ground acceleration of $0.152 \mathrm{~g}$ was recorded (Šket-Motnikar and Prosen, 2006).

The only existing microzonation of Kobarid area (Vidrih et al., 1991) was based on surface geological data, since no subsurface geological or geophysical information was available. It was prepared to be used together with the old seismic hazard map of Slovenia for a 500-year return period showing expected intensities on the MSK scale (Ribarič, 1987), in which Kobarid is estimated to have IX MSK intensity. This microzonation showed that the maximum expected intensity due to the effects of soft sediments can be increased by one intensity grade. For the whole basin the same intensity increment was ascribed, since no variations in sediments properties could be deduced from surface geological observations.

\section{Geological setting}

The Kobarid basin is located between two mountain ridges of the Julian Alps which extend in NW-SE direction (Fig. 1), and close to the outflow of tributary Idrija into the Soča river. SE of Kobarid the Soča valley developed along the Idrija strike-slip fault, the major tectonic feature in W Slovenia, which is more than $120 \mathrm{~km}$ long. W of Kobarid the basin extends in E-W direction for several kilometres. In general the basin is very narrow, at Kobarid it is only $700-800 \mathrm{~m}$ wide. The basement of the basin consists of Upper Triassic and Jurassic platform carbonates. Above them there is a succession of Cretaceous deep-water flysch or marly limestone (scaglia) (Buser, 1986). Quaternary sediments are represented from bottom to top by partly lithified glaciofluvial sediments, overlain by lacustrine chalk and glaciofluvial sand and gravel which forms terraces (Kuščer et al., 1974; Bavec et al., 2004). During the Holocene the lacustrine chalk was partly eroded and covered with younger sandy gravel, which is in some parts cemented into conglomerate. At the edge of the basin scree and debris are also found under steep slopes. The thickness of Quaternary sediments in the basin is not known because no drilling or geophysical investigations have been performed so far. It is roughly estimated that the maximum thickness in the deepest part does not exceed $100 \mathrm{~m}$. The slopes of the basin are presumably very steep.

Seismic velocities for different lithological units were derived from shallow seismic refraction measurements in the Bovec basin which has a similar geological setting. The Swaves velocities for glaciofluvial sand and gravel are 250 $450 \mathrm{~m} / \mathrm{s}$ and for Cretaceous flysch $1000-1400 \mathrm{~m} / \mathrm{s}$ (Gosar et al., 2001). Flysch rocks in the basement can be therefore considered as a seismic bedrock. Geological observations and microtremor investigations in the Bovec basin (Gosar, 2007) have shown that glaciofluvial sand and gravel are partly cemented in conglomerate in form of irregular shaped layers. These cemented layers can considerably change the fundamental frequency of sediments derived from microtremor measurements. Also lacustrine chalk has presumably higher S-velocities than unconsolidated sand and gravel, but no direct measurements are available. In general, fundamental frequencies obtained by microtremor measurements cannot be related to the total thickness of Quaternary sediments, but are highly influenced by layers of conglomerate or chalk. This represents a challenge for a site effects study, because no simple relation between sediments thickness and the related seismic response can be expected. In these conditions any site effects study based on drilling and extensive applied geophysical investigations would be very expensive. On the other hand the seismicity rate in the area is not so high to enable an effective and fast application of seismological methods. Therefore, we decided to perform a study based on microtremors measuremed on a relatively dense grid. 


\section{Methodology}

The microtremor HVSR method has been widely used for microzonation and site effect studies. Reviews on the method can be found in Bard (1999). However, the theoretical basis of the HVSR method is still debated, and different explanations have been given. Nakamura's (2000) "body waves" explanation is based on the S-wave resonance in soft sediment layers with minor or negligible influence of surface waves. More widely accepted (Bard, 1999; Bonnefoy-Claudet et al., 2006) is the "surface waves" explanation, by which HVSR is related to the ellipticity of Rayleigh waves, which is frequency dependent. HVSR therefore exhibits a sharp peak at the fundamental frequency of the sediments, when there is a high impedance contrast between the sediments and underlying bedrock. Criticism of the HVSR method is often related to the fact that there is no common practice for data acquisition and processing (Mucciarelli and Gallipoli, 2001). Attempts to provide standards have been made only recently (SESAME, 2004). Today it is widely accepted that the frequency of the HVSR peak reflects the fundamental frequency of the sediments. Its amplitude on the other hand depends mainly on the impedance contrast with the bedrock and cannot be used as a site amplification parameter. HVSR also does not provide any estimate of the actual bandwidth over which the ground motion is amplified. The main advantages of the HVSR method are a straightforward estimate of the resonance frequency of sediments without knowing the geological and S-velocity structure of the underground, and simple, low-cost measurements. By using the microtremor method, a much denser grid of measurements is possible than with any other method based on earthquake recordings, geophysical investigations or drilling. Any knowledge about the thickness and/or velocity of sediments and the comparison of HVSR results with other methods and with observed earthquake damage can significantly improve the reliability of the results (Bard, 1999).

The use of microtremors was later extended to the identification of the fundamental frequency of buildings and the soil-structure resonance (Mucciarelli et al., 2001; Gallipoli et al., 2004a). Damage enhancement and soil-structure resonance were recently studied using microtremors for the Umbria-Marche earthquake (Mucciarelli and Monachesi, 1998; Natale and Nunziata, 2004), the Thessaloniki earthquake (Panou et al., 2005), the Molise earthquake (Gallipoli et al., 2004b), the Krn Mountain earthquakes in the Bovec basin (Gosar, 2007), the Ilirska Bistrica area (Gosar and Martinec, 2009), and the Ljubljana basin (Gosar et al., 2010).

The theory and interpretation of ambient vibration results for buildings are not so structured and straightforward as they are for the free-field case. When measuring inside a given building in a densely populated area, one of the main difficulties is to detect and eliminate the effects of fundamental frequencies of the nearby free-field and of other buildings in the vicinity. In addition, when an instrument is not positioned in the mass centre, the torsional frequencies can mask the results. In the literature, most often only individual buildings or small samples of buildings have been considered. However, some useful advice and instructions for measurements in buildings and their interpretation are described in e.g. Gallipoli et al. (2004a), or Parolai et al. (2005). All measurements at higher floors of the building should represent building characteristics. Their curves should have the same form, their amplitude should increase with height and the peaks should be at the same frequency. Usually we may expect that longitudinal fundamental frequency is higher than the transverse one. When this is not the case, the mass centre may be distinct from the geometrical centre or heterogeneities in construction may exist (Gosar et al., 2010).

\section{Free-field microtremor measurements}

Microtremor measurements were performed in approximately $1 \mathrm{~km}^{2}$ large area which extends across the whole width of the basin in N-S direction and encloses the Kobarid town area (Fig. 2). In an approximate $100 \times 100 \mathrm{~m}$ grid altogether 106 free-field measurements were performed. The measuring locations were carefully selected to avoid as much as possible the influence of trees, buildings, underground structures and traffic. However, in the built urban environment this was not always possible. We used two Tromino seismographs (Micromed, 2005) composed of three orthogonal electrodynamic velocity sensors, a GPS receiver, digitizer and recording unit with a flash memory card. All parts are integrated in a common case to avoid electronic and mechanical noise, which can be introduced by wiring between equipment parts. Good ground coupling on soft soil was obtained by using long spikes mounted at the base of the seismograph. The sampling frequency was $128 \mathrm{~Hz}$ and the recording length at each point $20 \mathrm{~min}$.

The experimental conditions of microtremor measurements (e.g. Chatelain et al., 2008) were mainly favourable. The main difficulties arose from traffic and industrial noise. In the old town centre the free-field space between houses was also very limited. We avoided taking measurements on windy days, because the noise introduced by wind can severely affect the reliability of HVSR analysis.

HVSR analysis was performed in the following way. Recorded time series were visually inspected to identify possible erroneous measurements and stronger transient noise. Each record was then split into 30 s-long non-overlapping windows, for which amplitude spectra in the range $0.1-64 \mathrm{~Hz}$ were computed using a triangular window with $5 \%$ smoothing and corrected for sensor transfer function. HVSR was computed as the geometric average of both horizontal component spectra divided by the vertical spectrum for each window. From the colour-coded plot of HVSR functions for all 40 windows, the windows including strong transient noise were identified in order to be excluded from further 


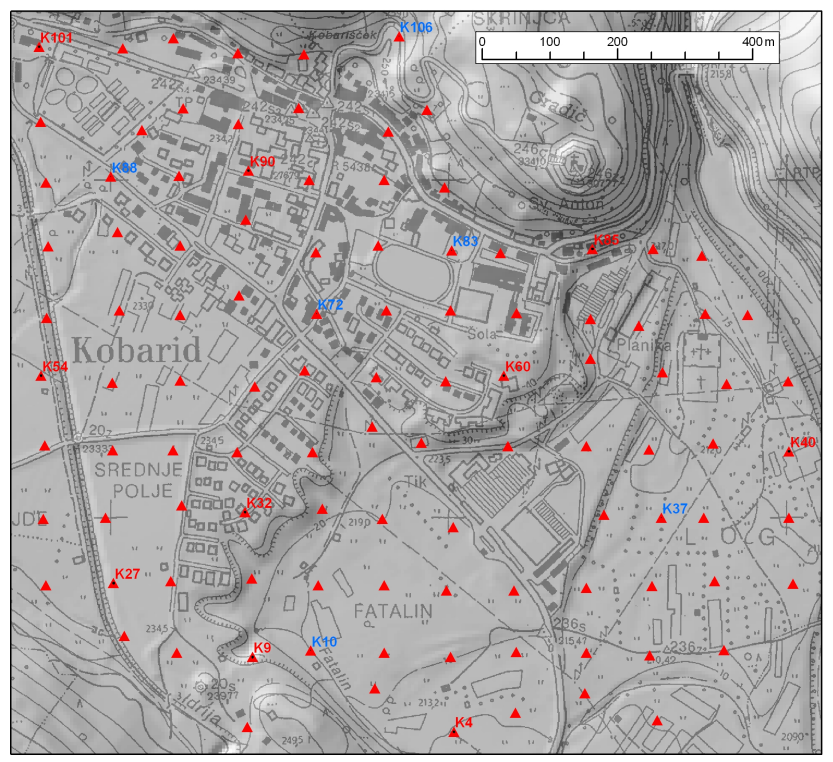

Fig. 2. Position map of microtremor free-field measurements (red triangles) in the Kobarid basin. Red labels indicates examples of HVSR analyses shown in Fig. 3 and blue labels examples shown in Fig. 4.

computation. Although Parolai and Galiana-Merino (2006) have shown that transients have little or no effect on HVSR, the effect of transient seismic noise on HVSR analysis is still debated. Finally, the average HVSR function of all windows with the corresponding 95\% confidence interval was computed. In addition, a directional HVSR analysis was performed in $10^{\circ}$ angular steps to identify possible directions of noise sources, but no preferential directions were established.

HVSR analyses of free-field measurements showed that most of them fulfil the criteria defined by the European SESAME project for reliable measurements (SESAME, 2004). Three of these criteria for a reliable HVSR curve are based on the relation of the peak frequency to the window length, the number of significant cycles and the standard deviation of the peak amplitude. The next six criteria for a clear peak are based on the relation of the peak amplitude to the level of the HVSR curve elsewhere, and standard deviations of the peak frequency and of its amplitude (the amplitude should decrease rapidly on each side). If all three criteria for a reliable curve and at least five criteria for a clear peak are fulfilled, the frequency of the peak is considered to be the fundamental frequency of sediments down to the first strong impedance contrast. The main reasons for the failure of the above criteria are: a) high level of noise, b) two or more peaks in a spectrum, or c) too small amplitude of the peak or flat spectral ratio. In cases in which the small amplitude of the HVSR peak caused failure to the criteria for a clear peak, we compared the results with adjacent measurements. If the frequencies of questionable peaks were comparable with the frequencies obtained at adjacent points, we kept them in the database.

Examples of HVSR graphs are shown in Figs. 3 and 4. Locations of these measurements are shown in Fig. 2. In general, clear peaks were obtained showing the broad range of fundamental frequencies between 2 and $22 \mathrm{~Hz}$ (Fig. 3). The temporal stability of the signal was in general good. This results in a narrow $95 \%$ confidence interval of average HVSR curves. In most cases there is a sharp peak in HVSR which is rather symmetrical (K32, K40, K90 and K101 in Fig. 3). An asymmetric shape with additional side peaks at frequencies higher than the frequency of the main peak is also common (K9, K27, K54 and K60 in Fig. 3). Some peaks are less sharp (K4 and K85 in Fig. 3) with some features which can be an indication of two closely spaced peaks. On the bedrock outcrop at the margin of the basin flat spectral ratios were obtained (K106 in Fig. 4) as expected. Among more complex shapes two peaks well separated in frequency (K37 and K83 in Fig. 4) are characteristic of the eastern part of the surveyed area. They indicate two impedance contrasts in the subsurface, first, shallow is most probably related to the conglomerate layer and the second, deep to the Cretaceous flysch in the bedrock. Some measurements show several peaks which are not well separated (K88 in Fig. 4) indicating complex setting, or a very broad peak (K72 in Fig. 4) which is characterized by wider $95 \%$ confidence interval. In general temporal stability is better at higher frequencies while $95 \%$ confidence interval is often wider at lower frequencies (e.g. K10 in Fig. 4).

The amplitudes of HVSR peaks are mainly in the range $3-8$, only in three cases they reach values between 9 and 9.5 (Fig. 5). In general there are more high peak amplitudes (above 6) at low fundamental frequencies $(1.8-4 \mathrm{~Hz}$ ), although this trend is not well expressed. Since low fundamental frequencies are related to deeper parts of the basin, this can be an indication of high impedance contrast between Quaternary sediments and Cretaceous flysch in the bedrock. On the other hand, high fundamental frequencies are presumably related to the parts of the basin where microtremor HVSR method detected shallower stiffer rocks (conglomerate or lacustrine chalk) within Quaternary sediments. It is likely that the impedance contrast is in this case lower. Nevertheless, more then one distinct impedance contrasts as observed in the eastern part of the survey area (two peaks in the HVSR curve) affect also the amplitude of individual peaks.

The data from 94 measuring points were used for drawing two maps: an iso-frequency map showing resonance frequencies of sediments (Fig. 6) and an iso-amplitude map (Fig. 7) showing amplitudes of HVSR peaks. For measurements which shows two clear HVSR peaks, we used the value of the peak with higher amplitude. Maps were drawn using GIS software and natural neighbour interpolation algorithm. The fundamental frequency of sediments shows a distribution in a range of $1.8-22.2 \mathrm{~Hz}$. It is clear from the map that the observed frequencies can be related to the 

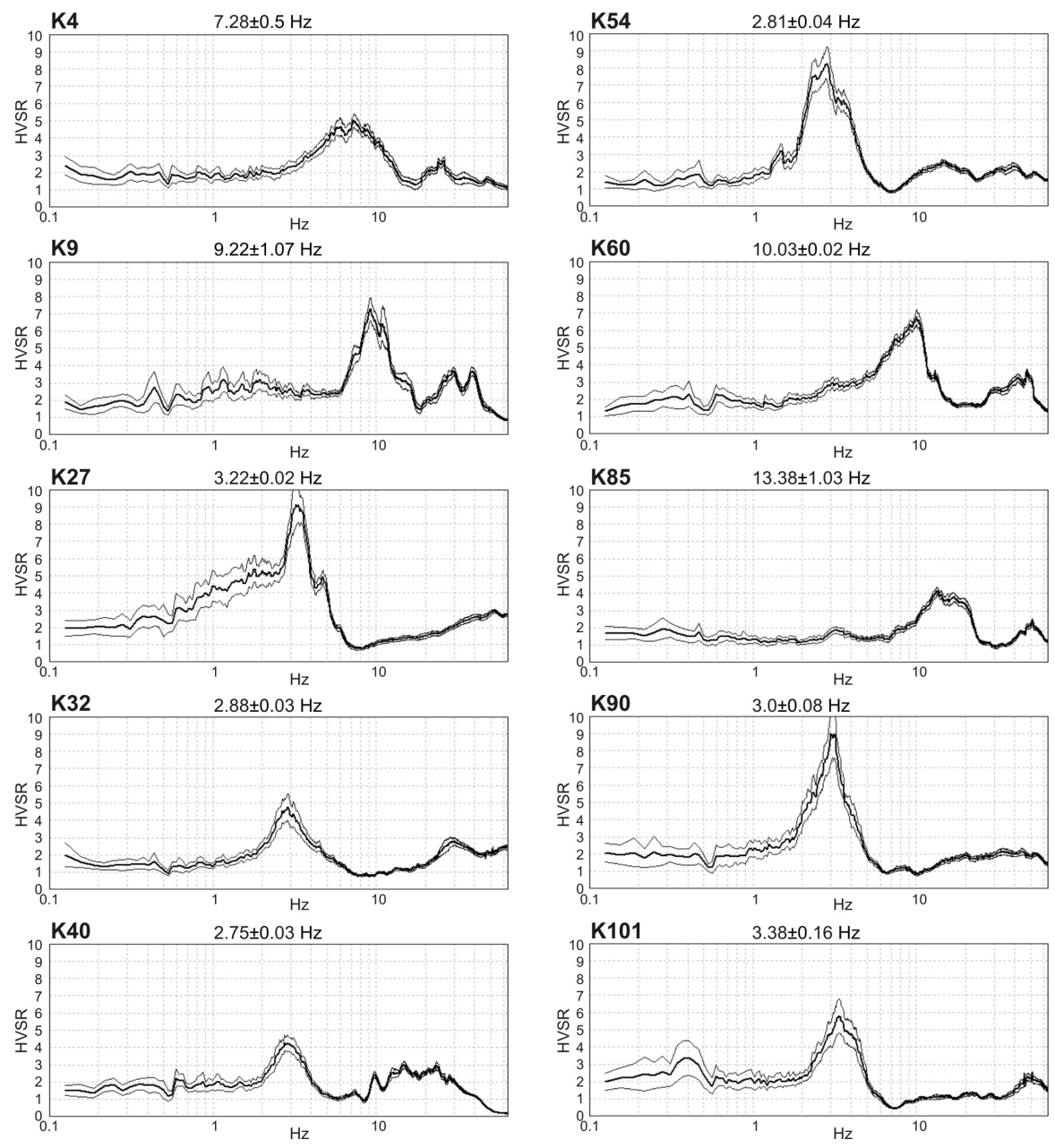

Fig. 3. Some examples of microtremor measurements (HVSR analyses) with clear peaks. Locations of measurements are shown in Fig. 2. Thin lines represent the $95 \%$ confidence interval.

total thickness of Quaternary sediments only to a limited extent, because the thickness was expected to be the greatest in the central part of the basin. There are two distinct regions of low frequencies $(1.8-3.6 \mathrm{~Hz})$, a large one in the western part and a very small one in the easternmost part of the basin. The seismic bedrock in these two regions is most probably represented by Cretaceous flysch. Both regions are separated by a broad transition zone characterized by frequencies in the range $6-13 \mathrm{~Hz}$. Without geophysical investigations or drilling it cannot be revealed if this transition zone of higher frequencies is caused by shallower Cretaceous bedrock which forms a saddle between two sub-basins or by the influence of lacustrine chalk which is likely to appear in the area. Since lacustrine chalk was partly eroded before the basin was filled with sand and gravel, its extent is not know. In the eastern part, within the transition zone, there is a narrow band of very high frequencies $(18.5-22.3 \mathrm{~Hz})$. Presumably it is caused by a shallow conglomerate layer. Measurements K37 and K83 (Fig. 4) taken in this area show two clear peaks, which are well separated in frequency. They indicate two impedance contrasts in the subsurface, the first is very shallow and the second rather deep. In general the amplitude of the peak at higher frequency is slightly higher than that of the peak at lower frequency. High frequencies (up to $19 \mathrm{~Hz}$ ) are visible also close to the $\mathrm{N}$ and $\mathrm{SW}$ margin of the basin. This is expected due to the thin deposits close to the border of the basin.

In the iso-amplitude map (Fig. 7) the highest values (up to 9.5) are located in the northern central part (the old town centre of Kobarid) and in the SW part (6-9) which is not urbanised yet. In the majority of the town area the HVSR peak amplitudes are between 3.5 and 7. The values are in general lower (3-4) in the SE part of surveyed area. However, it is known that the amplitude of HVSR peak is a less reliable parameter of microtremor measurements (SESAME, 2004). It can be therefore used only as a very rough indicator of impedance contrast between sediments and seismic bedrock. On average, amplitudes of HVSR peaks are larger in the western part of the basin which is characterized by lower fundamental frequencies. This can be therefore a 

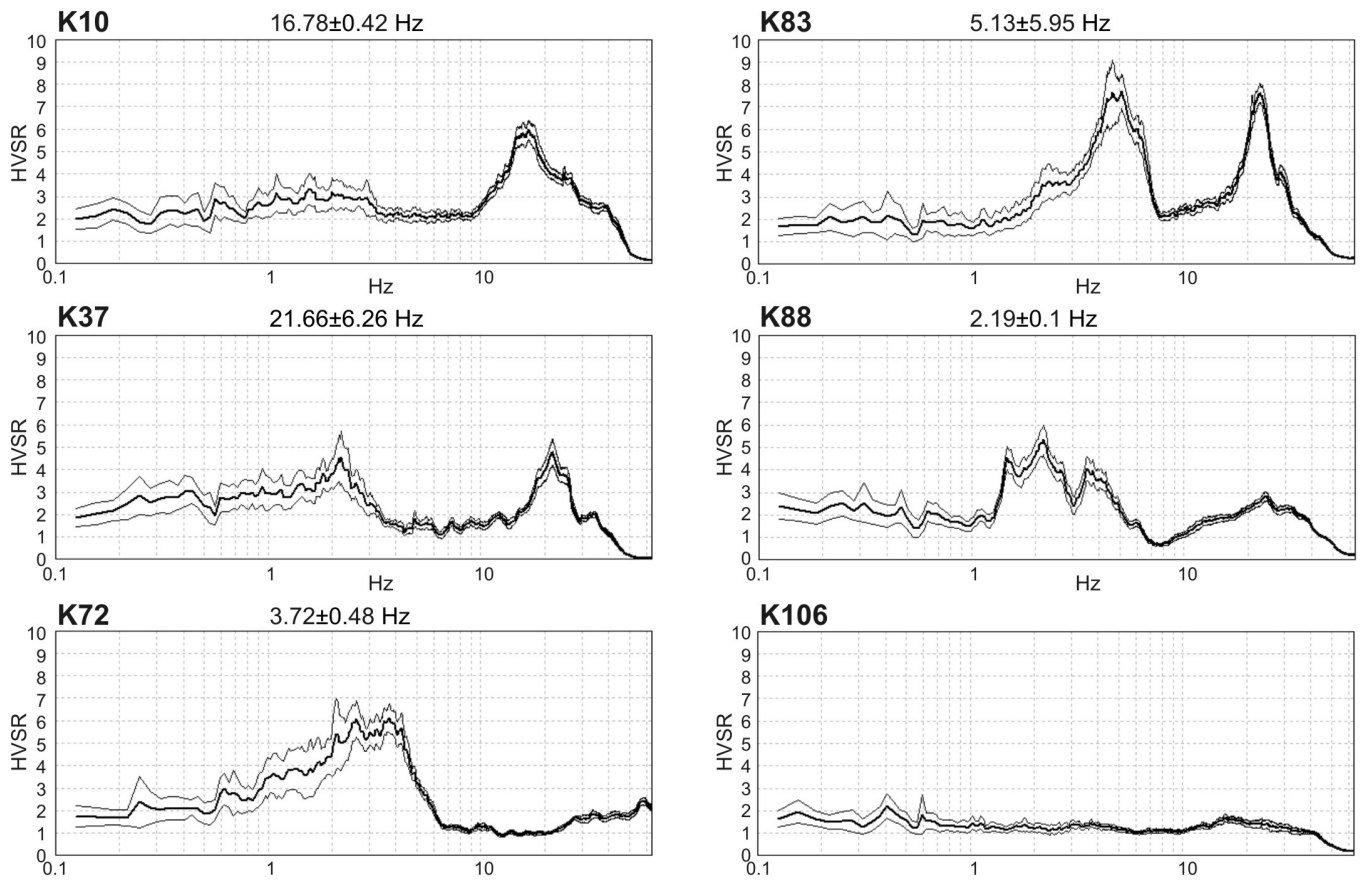

Fig. 4. Some examples of microtremor measurements (HVSR analyses) with more complex shape or flat spectral ratio. Locations of measurements are shown in Fig. 2. Thin lines represent the 95\% confidence interval.

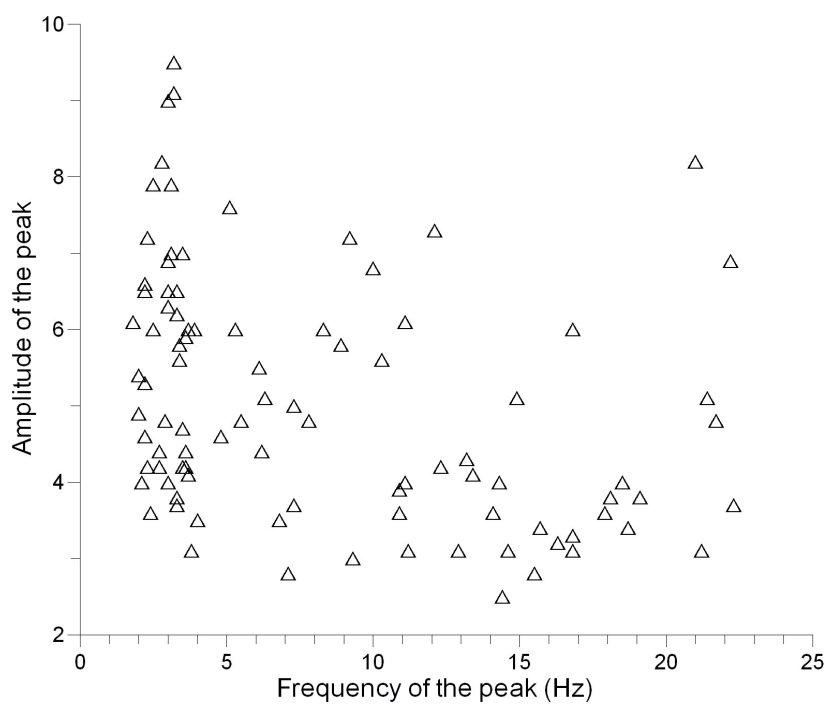

Fig. 5. Amplitude vs. frequency graph of HVSR peaks.

weak indication of relatively higher impedance contrast between sandy gravel and flysch rocks. The peak amplitudes along the narrow band of high frequencies in the eastern part are highly variable (3.3-8.2). This indicates that the shallow stiffer layer, presumably built of conglomerate, is not very homogeneous.

\section{Measurements inside buildings}

Two and three-story residential houses prevail in the area, with few multi-flat buildings of up to four-stories. Older houses are mainly of massive stone, while newer houses are mainly masonry with reinforced concrete floors. Measurements were performed in 19 selected buildings of different height in a range from two to four stories. The locations of the surveyed buildings are shown in Fig. 6 .

Microtremor measurements were performed on all floors of the building using the same instruments as in the freefield. The two horizontal components were oriented one in the longitudinal and one in the transverse directions of the building. The instrument was placed as close as possible to the mass centre of the building and close to a wall. Shorter spikes mounted at the bottom of the seismograph were used to enable precise levelling, but to avoid vibration of the unit. The recording length was $10 \mathrm{~min}$.

Each record was split into $10 \mathrm{~s}$ long non-overlapping windows for which amplitude spectra were computed using a triangular window with $3 \%$ smoothing. Windows including strong transient noise were excluded from further computation, although some investigations indicate that influence of transients is small (Yuen et al., 2002). Average amplitude spectra for each component were computed from selected windows.

For 14 measured houses (Table 2) it was possible to identify the longitudinal and transverse frequencies from both amplitude spectra. A good correspondence was found in the 


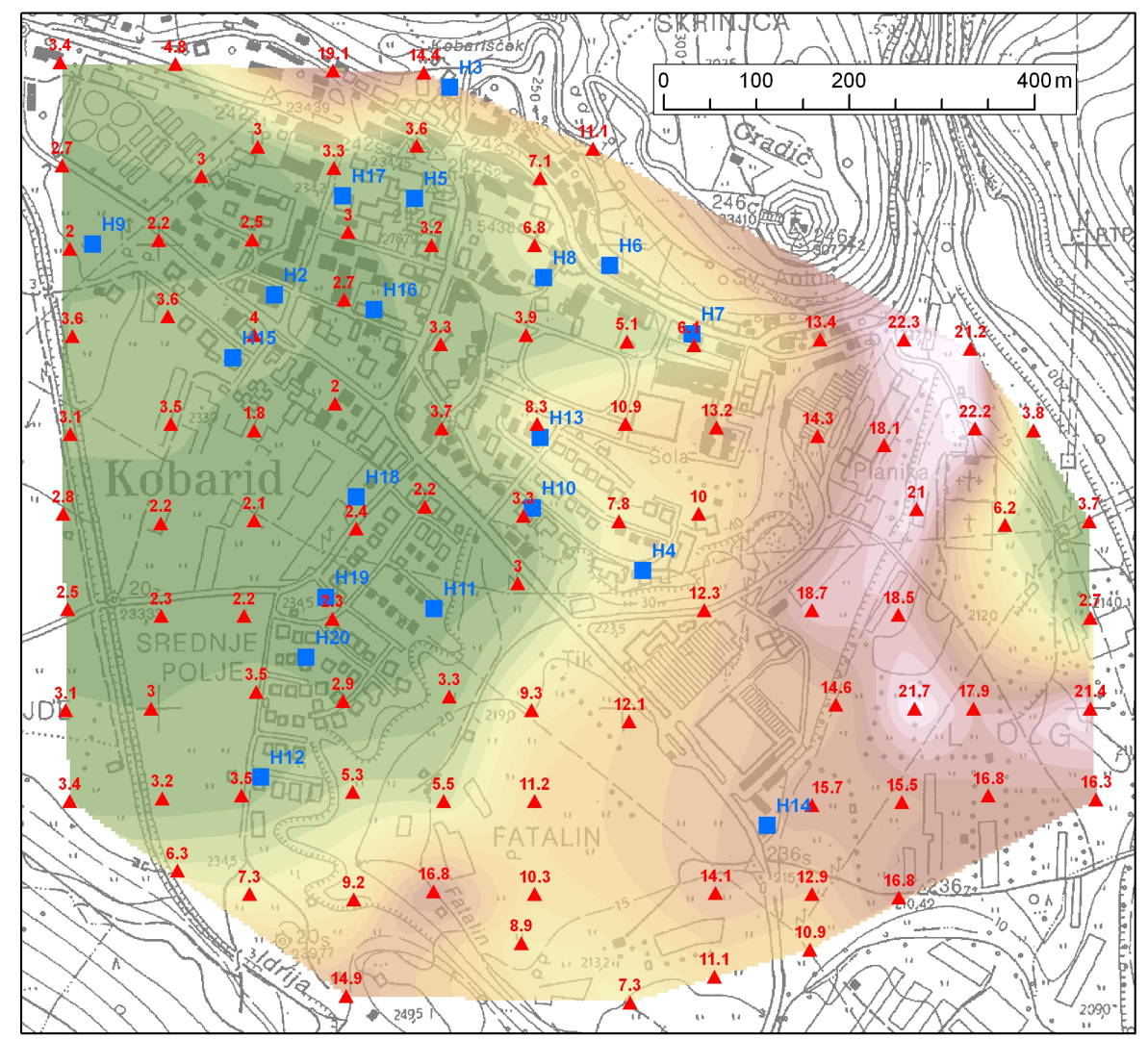

Freq. (Hz)

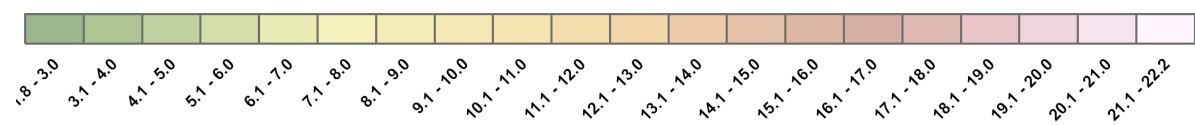

Fig. 6. Map of sediments resonance frequency derived from free-field microtremor data. Red labels indicate resonance frequency. Blue squares indicate location of buildings which were examined with microtremor measurements.

frequency of the peaks from measurements taken on different floors in the same building, showing an increasing amplitude response at higher levels. In the ground floor measurement the building response was often masked by the free-field frequency. Since it is not the purpose of this paper to study the dynamic behaviour of buildings, but to identify possible soil-structure resonances, only the results from the highest floor of each building are presented in this paper. Examples of amplitude spectra for six investigated houses are shown in Fig. 8. Main building frequencies are visible as clear isolated peaks on both measured components. The frequency difference between both directions is usually small, because most buildings have a rather symmetrical shape. In some spectra (H13, H16 and H18) artificial noise sources are visible at high frequencies characterized by box-type shaped peaks. At the location of each building the free-field sediments resonance frequency was derived from the iso-frequency map shown in Fig. 6.
The main results of microtremor measurements inside buildings are summarised in Table 2, together with the freefield frequency and an indication of whether soil-structure resonance is probable. The indication was chosen by applying the following criteria. First we select the building frequency that is closer to the free-field frequency and then we compute the ratio between them. If the difference is within $\pm 15 \%$, the danger of soil-structure resonance is high, if it is within $\pm 15-25 \%$, it is medium, and if it is higher than $\pm 25 \%$, then it is low. Among 14 buildings with established frequencies we found nine houses with low, three with medium, one with medium-high and one with high danger of soil-structure resonance. The building with established high soil-structure resonance (H12) is a three-story masonry house built in 1992. This house was slightly damaged in the 1998 and 2004 earthquakes. It is characterized by almost identical longitudinal $(3.7 \mathrm{~Hz})$ and transverse $(3.6 \mathrm{~Hz})$ frequencies, which reflect an almost symmetrical ground plan. The building is relatively new, built according to the latest building codes. Only slight damage is therefore expected, 


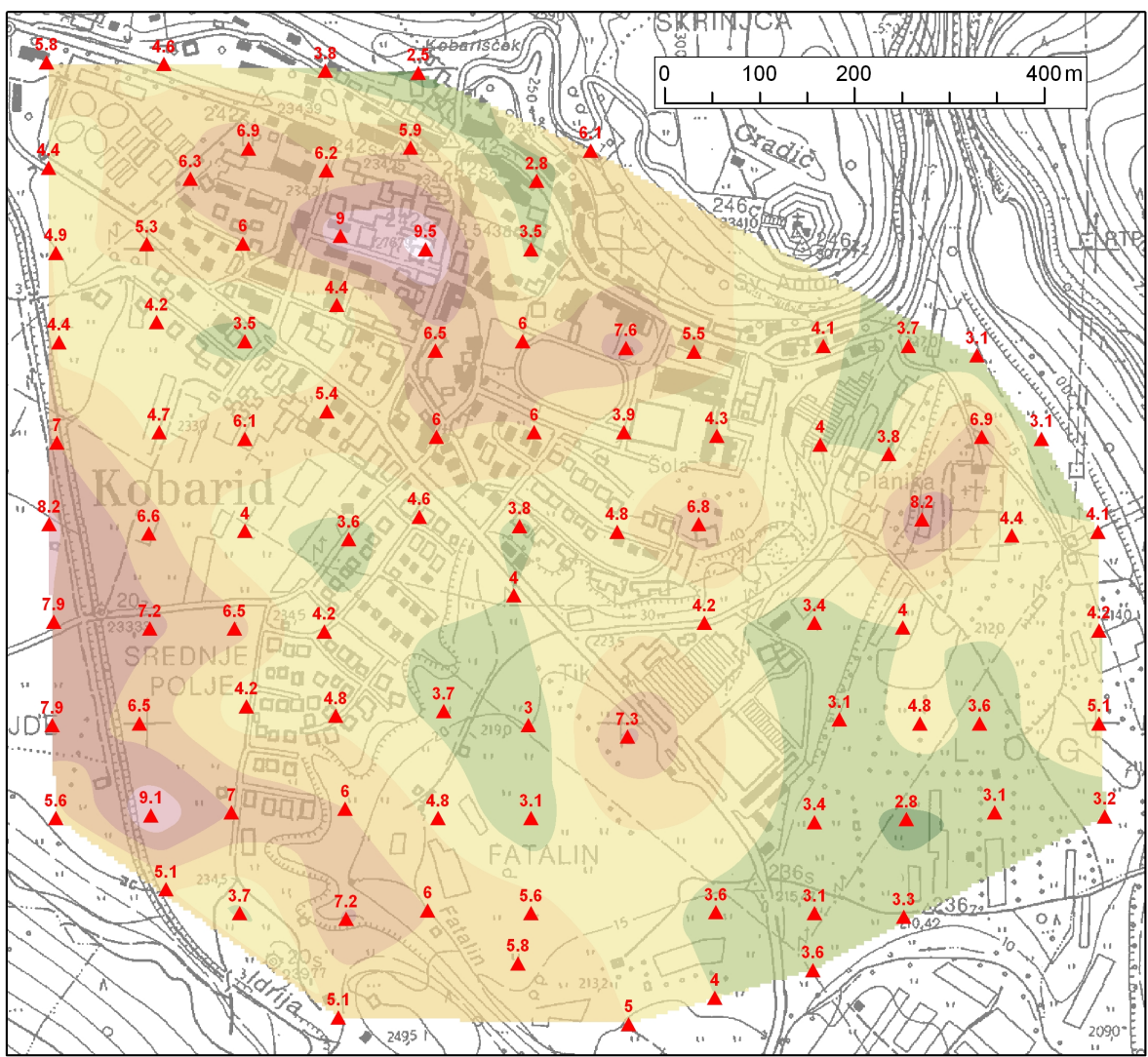

HVSR peak amplitude

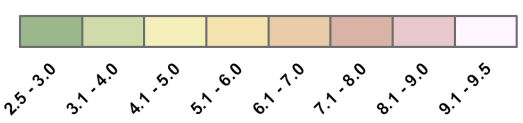

Fig. 7. Map of microtremor HVSR peak amplitudes. Red labels indicate peak amplitudes.

Table 2. Main results of microtremor measurements inside buildings. Locations of buildings are shown in Fig. 6.

\begin{tabular}{lrrrrl}
\hline Building & $\begin{array}{r}\text { Number of } \\
\text { stories }\end{array}$ & $\begin{array}{r}\text { Longitudinal } \\
\text { freq. }\end{array}$ & $\begin{array}{r}\text { Transverse } \\
\text { freq. }\end{array}$ & $\begin{array}{r}\text { Free-field freq. } \\
(\mathrm{Hz})\end{array}$ & $\begin{array}{l}\text { Danger of } \\
\text { soil-structure resonance }\end{array}$ \\
\hline H2 & 4 & 6.9 & 7.3 & 3.2 & low \\
H3 & 2 & 9.9 & 9.0 & 13.4 & low \\
H5 & 3 & 5.2 & 5.7 & 3.4 & low \\
H7 & 3 & 9.3 & 8.4 & 6.8 & medium \\
H8 & 2 & 7.7 & 6.9 & 5.9 & medium-high \\
H9 & 2 & 4.0 & 3.9 & 2.2 & low \\
H12 & 3 & 3.7 & 3.6 & 3.7 & high \\
H13 & 2 & 10.9 & 9.6 & 7.7 & medium \\
H14 & 2 & 11.9 & 11.8 & 13.7 & medium \\
H15 & 2 & 8.4 & 8.4 & 3.5 & low \\
H16 & 3 & 6.1 & 7.1 & 2.9 & low \\
H17 & 3 & 7.3 & 8.3 & 3.2 & low \\
H18 & 3 & 9.8 & 10.1 & 2.3 & low \\
H19 & 2 & 6.5 & 8.9 & 2.3 & low \\
\hline
\end{tabular}



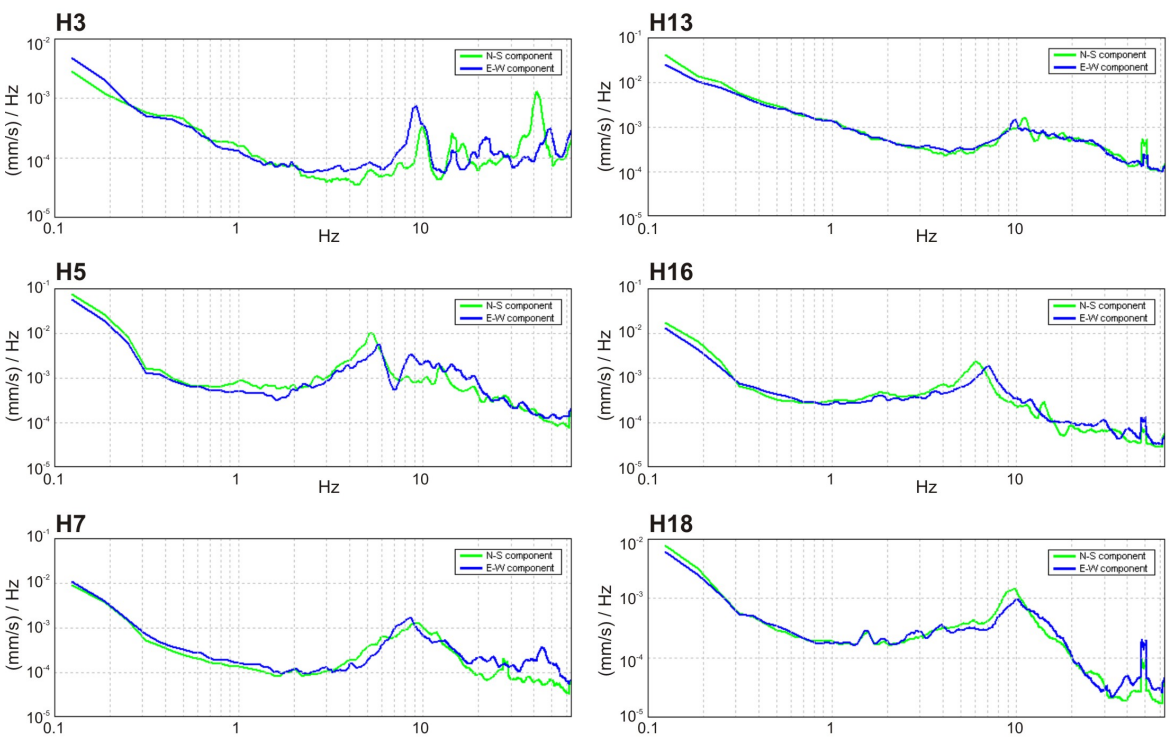

Fig. 8. Amplitude spectra of microtremor measurements inside six examined buildings. Their locations are shown in Fig. 6 . Green line represents longitudinal direction and blue line transverse direction of the building.

although the danger of soil-structure resonance is high. For building $\mathrm{H} 8$ medium-high danger of soil-structure resonance was ascribed because the difference with the free-field frequency is $17 \%$, close to the selected margin of $\pm 15 \%$. It is a two-story older house built of massive stone, which was moderately damaged in 1976 and 1998 earthquakes and later retrofitted. Four houses with established medium or high danger of soil-structure resonance (H7, H8, H12 and H13) are located in the transition zone between the western part of the basin characterized by low frequencies and eastern part characterized by higher frequencies. One additional twostory house with established medium danger of soil-structure resonance (H14) is characterized by high main building frequencies (11.9 and $11.8 \mathrm{~Hz}$ ), the highest found among all surveyed buildings. But this is not a typical residence house, because it is used also as an inn. Since it was built in 2006 only, no earthquake damage reports are available. At its location in the SE part of the basin the free-field frequency is $13.7 \mathrm{~Hz}$.

The graph of main building frequency vs. height (no. of stories) for all examined buildings is shown in Fig. 9. The range of main frequencies is $3.6-11.9 \mathrm{~Hz}$ and the average $7.7 \mathrm{~Hz}$. The difference between the longitudinal and transverse frequency is usually smaller then $1 \mathrm{~Hz}$. The ranges for two- and three-story buildings which prevail in the area are quite broad. Therefore, there is no clear dependence between the height of the building and the frequency between these two categories. This can be explained by various building typology, different ground plans and materials used. Thus, the frequency range between 4 and $11 \mathrm{~Hz}$ can be considered to be representative of the town. Very similar frequency ranges for two- and three-story houses were obtained in the Bovec basin (Gosar, 2007) and Ilirska Bistrica town (Gosar and Martinec,

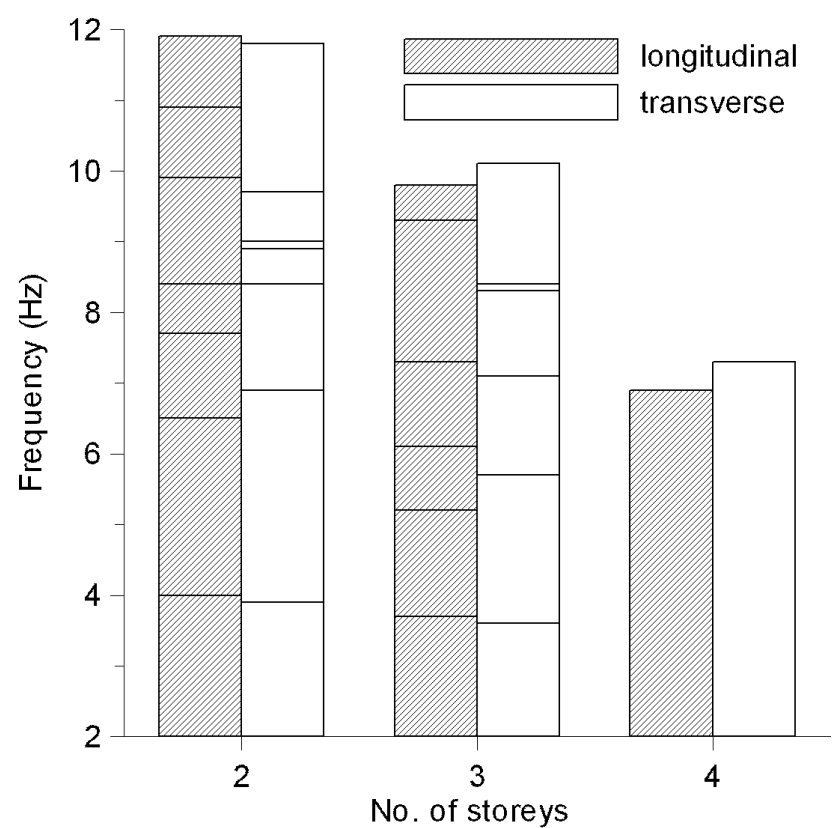

Fig. 9. Plot of building main frequency vs. height (no. of stories) for 14 examined buildings: 7 two-story, 6 three-story, and 1 four-story.

2009) which are characterized by similar building typologies. It is known that empirical relationship between the height of the building and main resonance frequency is more firm for reinforced concrete buildings (e.g. Gallipoli et al., 2010), which are very rare in Kobarid area. 


\section{Conclusions}

Since the geotechnical characteristics of soft sediments and their thickness are not known in the Kobarid basin, due to the lack of borehole or geophysical data, microtremor investigations have proved to be an effective tool for assessing the fundamental frequency of the sediments. The basin was surveyed with a dense grid of free-field measurements. This is especially important because the variations of the fundamental frequencies are considerable within the study area. Together with measurements taken inside buildings to assess their main resonance frequencies, the first attempt was made to assess the danger of soil-structure resonance in the area.

The iso-frequency map of sediments shows a distribution in a wide range of $1.8-22.2 \mathrm{~Hz}$. The observed frequencies can be related to the total thickness of Quaternary sediments (sand, gravel), deposited on the bedrock built of Cretaceous flysch, in the western part of the basin only. In the eastern part the fundamental frequencies are influenced by the presence of a shallow conglomerate layer inside sandy gravel or lacustrine chalk. The extent of these layers was not known before. Two distinct peaks in HVSR curve were obtained in this part, with considerably different frequencies, indicating shallow and deep impedance contrasts. In the easternmost part of the surveyed area low frequencies $(2.7-3.8 \mathrm{~Hz})$ were obtained in a few measurements, but investigations should be extended further to the east to characterize this presumably deep sub-basin. The highest HVSR peak amplitudes were obtained in the old central part of Kobarid and in the SW part, indicating high impedance contrast between sediments and the bedrock.

At the location of the strong-motion instrument installed in Kobarid, which recorded the 12 July 2004 earthquake $\left(M_{\mathrm{w}}=5.2\right.$, distance $\left.=7 \mathrm{~km}\right)$, the free-field frequency obtained from microtremor measurements is $3.6 \mathrm{~Hz}$. A peak ground accelerations of $0.152 \mathrm{~g}$ ( $\mathrm{N}$ component) and $0.133 \mathrm{~g}$ (E component) were recorded at predominant frequencies of 2.9 and $3.3 \mathrm{~Hz}$ respectively (Šket-Motnikar and Prosen, 2006). The resonance effects due to the interaction of seismic waves from local earthquakes with the soft sediments seem therefore likely in the area.

The buildings frequency range for two- and three-story houses which prevails in the area is $4-11 \mathrm{~Hz}$, with an average value of $7.7 \mathrm{~Hz}$. There is no clear dependence between the height of the building and frequency. This can be explained by varying building typology, different ground plans and construction materials used. For generalization of results, the danger of soil-structure resonance should be therefore sought in the whole frequency range of $4-11 \mathrm{~Hz}$. Since the majority of Kobarid area is characterized by lower (W part) or higher (E part) frequencies than the frequencies in this range, the danger of soil-structure resonance exists mainly in a relatively narrow transition zone. All houses with established medium (three houses) or high (two houses) dan- ger of soil-structure resonance are located in this transition zone.

The interpretation of microtremor free-field data is limited to fundamental soil frequency and gives no reliable indication of the amplification of seismic ground motion. HVSR also does not provide any assessment of the actual bandwidth over which the ground motion is amplified. The results can be enhanced and validated by independent information from boreholes and geophysical investigations. They would be important especially in the eastern part of the basin where microtremor measurements indicate more then one impedance contrasts at depth. Modelling of microtremor HVSR curves measured in a dense grid, based on sparse geophysical or borehole information, could be used in this case to generalize the obtained results.

Acknowledgements. The study was realized with the support of NATO SfP project 98057 "Assessment of seismic site amplification and seismic building vulnerability in FYR of Macedonia, Croatia and Slovenia", and research program P1-0011 financed by Slovenian Research Agency. The author is indebted to Jure Kokošin for his help in field measurements.

Edited by: M. E. Contadakis

Reviewed by: P. Suhadolc and another anonymous referee

\section{References}

Ambraseys, N., Smit, P., Sigbjornsson, R., Suhadolc, P., and Margaris, B.: Internet-Site for European Strong-Motion Data, online available at: http://www.isesd.cv.ic.ac.uk/, (last access: April 2010), 2002.

Bajc, J., Aoudia, A., Sarao, A., and Suhadolc, P.: The 1998 BovecKrn (Slovenia) earthquake sequence: Implications for earthquake hazard, Geophys. Res. Lett., 28(9), 1839-1842, 2001.

Bard, P. Y.: Microtremor measurements: a tool for site effect estimation?, in: The Effects of Surface Geology on Seismic Motion, edited by: Irikura, K., Kudo, K., Okada, H., and Sasatami, T., Balkema, Rotterdam, 1251-1279, 1999.

Bavec, M., Tulaczyk, S. M., Mahan, S. M., and Stock, G. M.: Late Quaternary glaciation of the Upper Soča River Region (Southern Julian Alps, NW Slovenia), Sed. Geol., 165, 265-283, 2004.

Bonnefoy-Claudet, S., Cornou, C., Bard, P. Y., Cotton, F., Moczo, P., Kristek, J., and Fäh, D.: H/V ratio: a tool for site effects evaluation. Results from 1-D noise simulations, Geophys. J. Int., 167, 827-837, 2006.

Buser, S.: Basic geological map of Yugoslavia 1: 100.000 - sheet Tolmin and Videm. Geological Survey of Slovenia, Ljubljana, 1986.

Cecić, I., Živčić, M., Jesenko, T., and Kolar, J.: Earthquakes in Slovenia in 2004, Potresi v letu 2004, 16-40, 2006.

Chatelain, J. L., Guillier, B., Cara, F., Duval, A. M., Atakan, K., and Bard, P. Y.: Evaluation of the influence of experimental conditions on $\mathrm{H} / \mathrm{V}$ results from ambient noise recordings, Bull. Earth. Eng., 6(1), 33-74, 2008.

Fitzko, F., Suhadolc, P., Aoudia, A., and Panza, G. F.: Constraints on the location and mechanism of the 1511 Western Slovenia 
earthquake from active tectonics and modeling of macroseismic data, Tectonophy., 404, 77-90, 2005.

Gallipoli, M. R., Mucciarelli, M., Castro, R. R., Monachesi, G., and Contri, P.: Structure, soil-structure response and effects of damage based on observations of horizontal-to-vertical spectral ratios of microtremors, Soil. Dyn. Earth. Eng., 24, 487-495, 2004a.

Gallipoli, M. R., Mucciarelli, M., Eeri, M., Gallicchio, S., Tropeano, M., and Lizza, C.: Horizontal to Vertical Spectral Ratio (HVSR) measurements in the area damaged by the 2002 Molise, Italy, earthquake, Earth. Spect., 20(1), 81-93, 2004b.

Gallipoli, M. R., Mucciarelli, M., Šket-Motnikar, B., Zupančič, P., Gosar, A., Prevolnik, S., Herak, M., Stipčevič, J., Herak, D., Milutinović, Z., and Olumćeva, T.: Empirical estimates of dynamic parameters on a large set of European buildings, Bull. Earth. Eng., doi:10.1007/s10518-009-9133-6, in press, 2010.

Gosar, A., Stopar, R., Car, M., and Mucciarelli, M.: The earthquake on 12 April, 1998 in Krn mountains (Slovenia): ground motion amplification study using microtremors and modelling based on geophysical data, J. Appl. Geophys., 47(2), 153-167, 2001.

Gosar, A.: Microtremor HVSR study for assessing site effects in the Bovec basin (NW Slovenia) related to $1998 M_{\mathrm{W}} 5.6$ and 2004 $M_{\mathrm{W}} 5.2$ earthquakes, Eng. Geol., 91, 178-193, 2007.

Gosar, A. and Martinec, M.: Microtremor HVSR study of site effects in the Ilirska Bistrica town area (S Slovenia), J. Earth. Eng., 13, 50-67, 2009.

Gosar, A., Rošer, J., Šket-Motnikar, B., and Zupančič, P.: Microtremor study of site effects and soil-structure resonance in the city of Ljubljana (central Slovenia), Bull. Earth. Eng., doi:10.1007/s10518-009-9113-x, in press, 2010.

Kastelic, V., Vrabec, M., Cunningham, D., and Gosar, A.: Neo - Alpine structural evolution and present day tectonic activity of the eastern Southern Alps: the case of the Ravne Fault, NW Slovenia, J. Struct. Geol., 30(8), 963-975, 2008.

Kuščer, D., Grad, K., Nosan, A., and Ogorelec, B.: Geology of the Soča valley between Bovec and Kobarid, Geologija, 17, 425476, 1974.

Lapajne, J., Šket-Motnikar, B., and Zupančič, P.: Design ground acceleration map of Slovenia. Potresi v letu 1999, 40-49, 2001.

Micromed: Tromino user manual, Micromed, Treviso, 2005.

Mucciarelli, M. and Monachesi, G.: A quick survey of local amplifications and their correlation with damage observed during the Umbro-Marchesan (Italy) earthquake of September 26, 1997, J. Earth. Eng., 2(2), 325-337, 1998.

Mucciarelli, M. and Gallipoli, M. R.: A critical review of 10 years of microtremor HVSR technique, Boll. Geof. Teor. Appl., 42, 255-266, 2001.
Mucciarelli, M., Contri, P., Monachesi, G., Calvano, G., and Gallipoli, M. R.: An empirical method to assess the seismic vulnerability of existing buildings using the HVSR technique, Pure. Appl. Geophys., 158, 2635-2647, 2001.

Nakamura, Y.: Clear identification of fundamental idea of Nakamura's technique and its applications, Proceedings of 12WCEE, Auckland, 2000.

Natale, M. and Nunziata, C.: Spectral amplification effects at Sel1lano, Central Italy, for the 1997-98 Umbria seismic sequence, Nat. Hazards, 33, 365-378, 2004.

Panou, A. A., Theodulidis, N., Hatzidimitriou, P., Stylianidis, K., and Papazachos, C. B.: Ambient noise horizontal-to-vertical spectral ratio for assessing site effects estimation and correlation with seismic damage distribution in urban environment: the case of city of Thessaloniki (Northern Greece), Soil. Dyn. Earth. Eng., 25(4), 261-274, 2005.

Parolai, S., Fäcke, A., Richwalski, S. M., and Stempniewski, L.: Assessing the vibrational frequencies of the Holweide hospital in the city of Cologne (Germany) by means of ambient seismic noise analysis and FE modelling, Nat. Hazards, 34, 217-230, 2005.

Parolai, S. and Galiana-Merino, J. J.: Effects of transient seismic noise on estimates of H/V spectral ratios, Bull. Seism. Soc. Am., 96(1), 228-236, 2006.

Perniola, B., Bressan, G., and Pondrelli, S.: Changes in failure stress and stress transfer during the 1976-77 Friuli earthquake sequence, Geophys. J. Int., 156, 297-306, 2004.

Ribarič, V.: Seismological map of Slovenia for 500 years return period. Seismological survey of Slovenia, Ljubljana, 1987.

SESAME: Guidelines for the implementation of the H/V spectral ratio technique on ambient vibrations: measurements, processing and interpretation, online available at: http://sesame-fp5.obs. ujf-grenoble.fr/Delivrables/Del-D23HV_User_Guidelines.pdf, (last access: April 2010), 2004.

Šket-Motnikar, B. and Prosen, T.: Accelerations in Posočje July 12 2004, Potresi v letu 2004, 105-113, 2006.

Vidrih, R., Godec, M., and Lapajne, J.: Potresna ogroženost Slovenije. Seismological Survey of Slovenia, Ljubljana, 1991.

Yuen, K. V., Beck, J. L., and Katafygiotis, L. S.: Probabilistic approach for modal identification using non-stationary noisy response measurements only, Earthq. Eng. Struct. Dyn., 31(4), 1007-1023, 2002.

Zupančič, P., Cecić, I., Gosar, A., Placer, L., Poljak, M., and Živčić, M.: The earthquake of 12 April 1998 in the Krn Mountains (Upper Soča valley, Slovenia) and its seismotectonic characteristics, Geologija, 44, 169-192, 2001. 